\title{
Urdimento
}

Revista de Estudos em Artes Cênicas E-ISSN: 2358.6958

\section{Grotowski: O decoro profissional como imperativo metodológico}

Filipe Pereira

\section{Para citar este artigo:}

PEREIRA, Filipe. Grotowski: o decoro profissional como imperativo metodológico. Urdimento, Florianópolis, v. 3, n. 39, nov./dez. 2020.

DOI: http:/dx.doi.org/10.5965/14145731033920200209 


\title{
Grotowski: o decoro profissional como imperativo metodológico
}

\author{
Filipe Pereira
}

\begin{abstract}
Resumo
Neste breve artigo defende-se que a dimensão ética, que é fundamental na metodologia proposta por Grotowski, resulta do extremar das mais simples regras de decoro profissional que são ensinadas nas escolas de teatro e postas em práticas pela maioria das companhias teatrais. Este aspecto é de extrema relevância, nas artes performativas como na sua pedagogia, quando considerada a dialéctica entre o "trabalho sobre si mesmo" e a alteridade. Aborda-se sucintamente o percurso artístico de Grotowski para defender uma dimensão ontológica da sua noção de Arte e demonstrar a coerência e linearidade do mesmo. Também concisamente, indicam-se as suas principais referências éticas e profissionais e como foram aplicadas na prática, realçando a importância conferida ao Outro. Termina-se argumentando em favor da ética como imperativo profissional e artístico no contexto grotowskiano, alicerçando-a no decoro profissional e na prática artística.
\end{abstract}

Palavras-chave: Grotowski. Decoro. Ética. Profissão. Metodologia.

\section{Grotowski: Professional decorum as a methodological imperative}

\begin{abstract}
In this brief article it is argued that the ethical dimension, which is fundamental to Grotowski's methodology, results from the radicalization of the simplest rules of professional decorum that are taught in drama schools and put into practice by most theater companies. This aspect is of extreme relevance, in the performing arts as in its pedagogy, when the dialectic between "work on oneself" and otherness is considered. Briefly, it is outlined Grotowski's artistic path, to argue an ontological dimension of his notion of Art and to demonstrate its coherence and linearity. Also concisely, are indicated his main ethical and professional references and how these were applied into practice, highlighting the importance given to the Other. To finish, it is claimed the ethics as a professional and artistic imperative in the grotowskian context, grounding it in the professional decorum and the artistic practice.
\end{abstract}

Keywords: Grotowski. Decorum. Ethics. Profession. Methodology.

${ }^{1}$ Performer, director de teatro, programador cultural e investigador em Etnografia da Performance. Colaborou com Jerzy Grotowski como investigador no seu Workcenter de Pontedera (Itália), entre 1990 e 1992. usufruindo de bolsa de investigação por parte da Fundação Gulbenkian e da Secretaria de Estado da Cultura (Portugal). Em 2015, concluiu o mestrado em Estudos Artísticos na Universidade de Coimbra. Doutorando em Estudos Artísticos - Arte e Mediações pela Universidade Nova de Lisboa, Faculdade de Ciências Sociais e Humanas, é investigador integrado no Instituto de Etnomusicologia (INET-md) e bolseiro da Fundação para a Ciência e a Tecnologia. josefilipeslp@gmail.com 


\section{Grotowski: El decoro profesional como imperativo metodológico}

\section{Resumen}

En este breve artículo se sostiene que la dimensión ética, fundamental en la metodología propuesta por Grotowski, resulta de la radicalización de las reglas más simples del decoro profesional que se enseñan en las escuelas de teatro y se ponen en práctica en la mayoría de las compañías de teatro. Este aspecto es sumamente relevante, tanto en las artes escénicas como en su pedagogía, cuando se considera la dialéctica entre "trabajo sobre uno mismo" y alteridad. Se aborda brevemente la trayectoria artística de Grotowski, para defender una dimensión ontológica de su noción de Arte y demostrar su coherencia y linealidad. También de manera concisa, se indican sus principales referentes éticos y profesionales y cómo estos se aplicaron en la práctica, destacando la importancia que se le da al Otro. Se termina defendiendo la ética como imperativo profesional y artístico en el contexto grotowskiano, basándola en el decoro profesional y en la práctica artística.

Palabras clave: Grotowski; Decoro; Ética; Profesión; Metodología. 
Em 2018, o Professor Paulo Filipe Monteiro, da Universidade Nova de Lisboa, convidou-me a ministrar um curso teórico-prático sobre Grotowski, dirigido a estudantes de pós-graduação. Alguns desses alunos estavam a desenvolver dissertações que incidiam sobre aspectos do trabalho do mestre polaco e tinham dificuldade em entender e articular as noções práticas que encontravam em textos de origem diversa.

Fui aluno de Grotowski e pesquisador no seu Workcenter em Pontedera, entre 1990 e 1992. Depois, fundei um colectivo com que continuei a trabalhar sobre a Arte como Veículo². Durante mais de 25 anos realizei um grande número de acções de formação: para profissionais, amadores ou estudantes das artes performativas; para crianças, adultos e adolescentes; incidindo sobre aspectos gerais da técnica do actor ou sobre questões específicas, como a voz, o trainingfísico, a criatividade, etc.; ou como complemento formativo para diferentes profissionais, como professores, terapeutas ou comunicadores, entre outros. Apesar de ser do conhecimento geral a determinante influência que a aprendizagem com Grotowski teve no meu percurso, nunca ensinei especificamente sobre ele ou em seu nome. A razão é simples: com Grotowski, sobretudo, aprendi a aprender; ele não me ensinou nada, tão só criou as condições para que eu entendesse que a aprendizagem era uma questão minha, que eu próprio tinha que resolver. Foi isso que sempre tentei fazer nas acções de formação que orientei: criar condições para que o aluno perceba que eu não tenho nada para the ensinar, é ele que, principalmente, tem que desaprender noções supérfluas, ultrapassar bloqueios, libertar-se. Não fazia, pois, sentido trazer Grotowski, ou quem quer que fosse, para essa equação.

Encontrava-me agora perante um desafio: como explicar o trabalho de Grotowski, que deixou bem claro que o conhecimento não pode ser compreendido, somente obtido pela prática? E, num curso de curta duração, qual aspecto da complexa metodologia usar como estruturante do processo?

Reflectindo sobre as técnicas que iria transmitir nesse breve curso,

${ }^{2}$ Acto - Instituto de Arte Dramática, activo entre 1992 e 2006 e sediado em Aveiro e Estarreja. 
contextualizando-as no percurso artístico de Grotowski e na minha própria experiência da sua aplicação no âmbito criativo, tornou-se para mim claro que, neste contexto, é a dimensão ética que congrega e fundamenta toda a prática.

Continuei a reflectir sobre este assunto; troquei correspondência com vários estudiosos do trabalho de Grotowski e reli os seus textos. Neste breve artigo pretendo dar conta das conclusões que, não sendo definitivas, podem ajudar a lançar luz sobre este tema, pouco explorado nos estudos grotowskianos mas decerto muito relevante.

Mota Lima chamou-me a atenção ${ }^{3}$ para que tudo em Grotowski tem uma dimensão artesanal, e que é assim também para a ética. Discorre sobre esse tema no seu livro (2012), chamando também a atenção para o erro em que consistiria tentar compreendê-lo a partir de uma única ideia central. A sua ética, como a metodologia, é construída na prática, na experimentação exaustiva. "/l faut essayer", é preciso experimentar, era uma das suas alocuções mais frequentes. É, pois, um exercício de experimentação que aqui faço, tentar perceber a dimensão ética de Grotowski como decorrente do decoro profissional, deixando em aberto que se pode abordar a mesma matéria sob outros pontos de vista.

\section{O percurso de Grotowski: a dimensão ontológica da Arte}

Grotowski foi uma das mais importantes figuras do Teatro e das Artes Performativas do século XX, à escala global. Em 1996, Robert Findlay estimava que a bibliografia mundial sobre Grotowski teria aproximadamente 20.000 entradas (Wolford, 1996). O ano de 2009 foi proclamado Ano de Grotowski pela Unesco. Slowiak e Cuesta afirmam que Grotowski se equipara a Stanislavski, Meyerhold e Brecht como um dos quatro grandes directores de teatro do século XX. "Mas enquanto é geralmente compreendido que Stanislavski transformou a actuação, Meyerhold a encenação e Brecht a dramaturgia, a influência de Grotowski no ofício

${ }^{3}$ Comunicação pessoal, Agosto de 2018. 
não é tão imediatamente reconhecível”. (Slowiak e Cuesta, 2007, p. 64).

Importa, pois, perceber o seu trajecto e as suas motivações. Para Grotowski a arte tem uma função de auto-realização, para a qual é mais importante o processo do que o resultado: "Nesta luta pela verdade de nós próprios, neste esforço para arrancar a máscara quotidiana, o teatro, com a sua percepção carnal, sempre me pareceu uma espécie de provocação” (Grotowski, 1975 [1968], p. 19).

Monique Borie (1978), entende que para Grotowski a arte é não só um instrumento de realização, mas também a posição a partir da qual ele interroga o pensamento mítico, numa demanda em tudo igual à da hermenêutica. A procura de Grotowski, como a da interpretação da lenda, é pois sobre a problemática do ser, situando-se portanto num plano ontológico.

Quando me refiro a ontologia, tenho em mente a noção geral de uma metafísica ontológica, isto é, a disciplina que estuda o carácter fundamental do ser, o que é ser (Abbagnano, 2007). Mas Grotowski não era um filósofo: a sua demanda era prática e o seu discurso dirigia-se a performers, fazedores 5 . Para entender as suas palavras temos que as situar no contexto do seu percurso. Não sendo o propósito deste texto apresentar a história da vida de Grotowski, farei apenas um resumo que permita enquadrar o objecto da análise.

A sua actividade teatral foi fulgurante: produções como Dr. Faustus (1963), O Príncipe Constante (1965), ou Apocalypsis Cum Figuris (1969), por exemplo, suscitaram grande interesse a nível internacional e expectativas quanto às propostas ligadas às noções de teatro pobre e de actor santo. Foi por isso que em 1969 o anúncio pelo Teatr-Laboratorium da renúncia às produções teatrais foi recebido com surpresa e perplexidade: Grotowski abandonava o teatro quando o futuro era tão promissor! E, no entanto, esse era o desenvolvimento lógico quando considerada uma das principais motivações que o orientavam: ultrapassar a barreira entre o actor e o espectador e democratizar a prática artística. Esses eram os fundamentos do movimento para uma Cultura Activa, uma proposta de

${ }^{4}$ But while it is generally understood that Stanislavsky transformed acting, Meyerhold, directing, and Brecht, playwrighting, Grotowski's influence on the craft is not so instantly recognizable. (Tradução nossa)

${ }^{5}$ Grotowski usa frequentemente o termo doer, em inglês, sem o traduzir. 
Grotowski que enformou a actividade do Teatr-Laboratorium durante a década de 1970 e fundamentou o Teatro da Participação, ou Parateatro. Em termos gerais: a Cultura, que pode ser entendida como arte e criatividade, é uma acção "que dá um sentido de realização à vida, uma extensão das suas dimensões, é necessária para muitos e no entanto continua a ser o domínio de muito poucos"6 (Grotowski, 1976 apud Kumiega, 1985, p. 201). Tratava-se, pois, de acabar com o consumo passivo da arte e promover a participação daqueles que, até então, tinham sido os espectadores. Nos projectos parateatrais, que decorriam durante vários dias em locais isolados no campo, pessoas externas ao teatro participavam em experiências performativas, enquadrados pela equipa do Teatr-Laboratorium. Mas Grotowski não tinha contado com a falta de preparação técnica dos participantes e, se nos primeiros tempos, com poucos participantes exteriores, os resultados eram muito satisfatórios, à medida que se faziam versões com o intuito de incluir mais participantes, a acção "degenerou, em certa medida, numa sopa emotiva entre as pessoas, ou melhor, numa espécie de animação"7 (Grotowski, 1995, p. 120).

A grande lição que Grotowski tiraria do Parateatro prende-se com a impossibilidade do diletantismo: "Não é a boa vontade que vai salvar o trabalho, mas a maestria. Obviamente, quando temos a maestria, aparece a questão do coração. Coração sem maestria é uma merda. Quando a maestria existe, devemos lidar com o coração e com o espírito"8 (Grotowski, 1997b [1986], p. 297).

Em 1976, ainda com projectos parateatrais a decorrer, o Teatr-Laboratorium inaugurou a fase do Teatro das Fontes. Como resultado das suas viagens, Grotowski tinha contactos com inúmeros indivíduos e colectivos que desenvolviam diversas práticas performativas, no domínio estético, mas não só. O novo projecto recorreu a esses contactos para estabelecer um estudo sistemático, não das diferentes formas performativas, não das diversas técnicas, mas do que

${ }^{6}$ which gives a sense of fulfillment of life, an extending of its dimensions, is needed by many, and yet remains the domain of very few. (Tradução nossa)

${ }^{7}$ descended to some extent into an emotive soup between the people, or rather into a kind of animation. (Tradução nossa)

${ }^{8}$ It is not goodwill which will save the work, but it is mastery. Obviously when mastery is here, appears the question of heart. Heart without mastery is shit. When mastery is here, we should cope with the heart and with the spirit. (Tradução nossa) 
está antes: "o que procuramos neste Projecto são as fontes da técnica das fontes e essas fontes devem ser extremamente simples. Tudo o resto desenvolveu-se posteriormente e diferenciou-se de acordo com os contextos social, cultural e religioso". 9 (Grotowski, 1997a, p. 261).

Participantes transnacionais, profundamente envolvidos nas suas práticas tradicionais, individualmente ou integrando os seus colectivos, tomavam parte em encontros com várias semanas de duração. Nestas ocasiões, que decorreram em vários locais na Polónia e em Itália, mas também no Haiti, na reserva dos Huichols no México, no território Yoruba na Nigéria, em Bengala e noutros locais, procuravase identificar elementos performativos comuns às diferentes tradições e técnicas, as suas eventuais origens comuns.

A grande ruptura em relação à estratégia do parateatro é a individualidade do trabalho. "No Teatro das Fontes cada um está 'sozinho com os outros'. Mesmo se trabalham lado a lado, estão na solidão”. ${ }^{10}$ (Grimes, 2997, p. 271).

Em suma, um trabalho individual de especialistas em técnicas performativas tradicionais que procuravam, não na sua tradição, mas no que podia estar antes da tradição e da cultura, na origem. Também neste propósito se consegue perceber uma dimensão ontológica: “[...] trata-se do ser, da condição do Ser [...] É o que não recebemos dos outros, o que não vem do exterior, que não é aprendido". 11 (Grotowski, 1988, p. 54).

O Teatro das Fontes prolongou-se até 1982 quando, por desacordo com a imposição da lei marcial na Polónia no ano anterior, Grotowski optou pelo exílio voluntário, condicionando a continuidade do projecto.

Em 1983, Grotowski lançou um novo projecto, agora sem o enquadramento do Teatr-Laboratorium e num contexto que the era estranho: na Universidade da

\footnotetext{
${ }^{9}$ what we search for in this Project are the sources of the technique of sources, and these sources must be extremely unsophisticated. Everything else developed afterwards, and differentiated itself according to social, cultural or religious contexts. (Tradução nossa)

${ }^{10}$ In the Theatre of Sources one is 'alone with others'. Even though people work alongside one another in it, they are in solitude. (Tradução nossa)

${ }^{11}$ il s'agit de l'être, de l'êtreté. [...] C'est ce qu'on n'a pas reçu des autres, ce qui ne vient pas de l'extérieur, qui n'est pas appris. (Tradução nossa)
} 
Califórnia/Irvine iniciou a pesquisa sobre o Drama Objectivo. O programa apresentava-se nos seguintes termos: "Drama objectivo diz respeito àqueles elementos de rituais antigos que têm um impacto preciso, e portanto objectivo, nos participantes, para além do mero significado teológico ou simbólico”12 (Wolford, 1996, p. 9). O projecto durou pouco tempo sob a direcção de Grotowski que, em 1986 se instalou em Pontedera, Itália, para aí estabelecer o seu Workcenter e dar início à última fase do seu trabalho, que ficou conhecida como Arte como Veículo.

No pequeno ensaio incluído no livro de Thomas Richard (1995), e que constitui uma das principais fontes escritas sobre o assunto, explica-nos que a Arte como Veículo poderia também ser chamada de objectividade do ritual ou Artes Rituais. Ritual entendido não como uma cerimónia ou uma celebração e muito menos uma improvisação. A referência ao ritual situa-se na objectividade dos seus elementos, que são instrumentos para trabalhar sobre o corpo, o coração e a cabeça do fazedor (Grotowski, 1995).

A Arte como Veículo é o outro extremo de uma cadeia que liga o teatro como espectáculo aos ensaios com vista ao espectáculo, estes às improvisações anteriores à construção do espectáculo... O que principalmente a distingue do teatro é o lugar da montagem, que é feita, "não na percepção dos espectadores, mas no artista que faz"13 (Grotowski, 1995, p. 124). É uma montagem orgânica, que responde às pulsões vitais do performer e as desafia. A Arte como Veículo é o corolário da carreira de Grotowski e da sua motivação original: a Arte serve para nos realizarmos.

O percurso de Grotowski aqui sumariamente descrito é sintetizado por Schechner da seguinte forma: o trabalho sobre si próprio levou ao abandono do teatro e conduziu ao Parateatro; a procura de algo que fosse transcultural e essencial remeteu ao Teatro das Fontes; destilar essas fontes em acções

12 Objective drama is concerned with those elements of ancient rituals of various world cultures which have a precise and therefore objective impact on participants, quite apart from solely theological or symbolic significance. (Tradução nossa)

${ }^{13}$ not in the perception of the spectators, but in the artists who do. (Tradução nossa) 
performativas levou ao Drama Objectivo e à Arte como Veículo (Schechner, 1997).

Para Grotowski o trajecto é linear: "A linha é perfeitamente directa, procurei sempre prolongar a investigação, mas chegado a um certo ponto, para fazer um passo em frente, é preciso alargar o campo"14 (Thibaudat, 1995, p. 28).

Ao alargar do campo, aos desenvolvimentos que as suas noções práticas foram tendo ao longo do tempo, Mota Lima dedica uma obra de referência (2012). Mas é a sua coerência e linearidade que mais me interessam agora: permitem-me analisar as suas palavras, independentemente de quando foram proferidas, e aplicá-las ao conjunto da sua prática que, como fica exposto, se orientava por uma motivação ontológica, e aqui identificar um primado ético que the confere uma coerência impar.

\section{As fontes e a prática}

Grotowski via-se como um continuador de Stanislavski e a sua base de trabalho era uma versão desenvolvida da metodologia das acções físicas. O principal factor que the permitiu desenvolver a linha metodológica iniciada pelo mestre russo no final da sua vida foi o facto de Grotowski não estar constrangido pelas exigências do teatro realista em que Stanislavski laborava (Richards, 1995). Trabalhando sobre as acções físicas e sobre a organicidade, outra noção obtida de Stanislavski, Grotowski chegou às impulsões físicas e aos desenvolvimentos que estas trazem à metodologia: o corpo-memória, o corpo antigo, a consciência vigilante, o corpo-vida. Não é este o lugar para aprofundar as questões técnicas do trabalho de Grotowski; importa apenas assinalar o definitivo peso da influência de Stanislavski que, como fica claro em todos os seus escritos, dava uma suprema importância à ética profissional no trabalho teatral.

Outra importante influência foi a do Reduta, grupo de teatro polaco de vanguarda dirigido por Juliusz Osterwa, que funcionou entre 1919 e 1939. Ao ponto

${ }^{14}$ La lignée est parfaitement directe. J'ai toujours cherché à prolonger l'investigation, mais arrivé à un certain point, pour faire un pas en avant, il faut élargir le champ. (Tradução nossa) 
de, em 1966, o Teatr-Laboratorium adoptar o logótipo do Reduta, um laço formado por duas elipses interceptadas. Para Burzynski e Osinski (1979), tratava-se sobretudo de uma referência ética dentro do contexto profissional. Grotowski disse: "Em termos de ethos profissional e do modo de encarar a arte como uma empresa que envolve a dedicação da própria vida, sinto que éramos uma continuação directa dos princípios básicos de Osterwa e do Reduta”15 (Grotowski, 1993, apud Osinski, 2008, p. 55). Burzynski e Osinski (1979) entendem que o que distinguia o Reduta era a sua estruturação como colectivo, a sua vocação para a pesquisa e a recusa do recurso fácil do teatro comercial.

Uma outra influência que é notória em Grotowski é a de Martin Buber, cujos livros leu ainda na juventude. "Buber era um dos autores favoritos de Grotowski. Os temas do encontro autêntico, do sacrifício e do risco que perpassam pela discussão de Grotowski podem também ser encontrados no conceito de 'Eu - Tu' de Buber”16 (Lavy, 2005, p.180). Parece ser aí que Grotowski vai beber a noção de parceiro seguro em que reside a oportunidade para um renascimento (Grotowski, 1975 [1968]), e que pode ser ligada ao conceito de Eu e Tu em Buber. O que Buber nos diz é que só um ser humano total e uno pode ir com sucesso ao encontro do Outro e que essa reunião é o berço da Verdadeira Vida (1937 [1923]).

Esta dimensão de alteridade (Coelho, 2009) é fundamental para a compreensão da sua dimensão ética, pois é ela que, em última análise, a alicerça. O Outro é considerado a diferentes níveis, desde o espectador, que não deve ser referido com um substantivo colectivo como público ou audiência ${ }^{17}$, ao cidadão, a quem dedicou o seu activismo político. Mas o Outro, que fundamenta todo o primado ético em Grotowski, é esse companheiro do trabalho sobre si próprio, um trabalho individual, em solidão... mas uma solidão entre os outros e para os outros.

\footnotetext{
${ }^{15}$ In terms of [their] professional ethos and their way of looking at art as an enterprise that involves one's life dedication, it gives me a feeling that we were a direct continuation of the basic principles of Osterwa and Reduta. (Tradução nossa)

${ }^{16}$ Buber was among Grotowski's favorite authors. The themes of authentic encounter, sacrifice, and risk which run through Grotowski's discussion can also be found in Buber's concept of I-Thou. (Tradução nossa)

${ }^{17}$ Público é um rebanho!" disse um dia na minha presença, "O espectador tem sempre que ser tratado com o respeito que nos merece um indivíduo".
} 
A este ponto, parece-me necessário explicitar algumas noções. Por decoro profissional entendo o conjunto de normas práticas que decorrem do respeito por si mesmo e pelos outros, dentro do contexto profissional. No teatro, ser pontual, não fazer barulho enquanto os outros ensaiam, tratar os adereços com cuidado, por exemplo, são regras práticas que se aprendem desde cedo e que compõem uma ética pragmática que, apesar de normativa, não estabelece princípios morais. Veremos como Grotowski denuncia a moralidade assente em princípios normativos e espontaneamente transforma este decoro profissional num imperativo metodológico.

Jennifer Kumiega advertiu-me ${ }^{18}$ de que, para entender a ética profissional de Grotowski é necessário considerar outros aspectos: o modo como viveu a sua vida ou a forma como geriu as relações com aqueles com quem trabalhou. Grotowski levou uma vida espartana: "A pobreza foi inicialmente uma prática neste teatro; só mais tarde foi elevada à dignidade de estética"19 (Kott, 1997, p. 134). Nos seus últimos anos vivia em condições ascéticas (Wolford, 1997a). A pobreza, ou pelo menos a demarcação face às condições económicas, é um aspecto importante no percurso de Grotowski que nunca esperou pelas condições ideais nem ficou refém dos sucessos alcançados. De resto, parece não ter tido uma vida pessoal separada da vida profissional.

Para nos dar conta da forma como se norteava nas relações com os companheiros de trabalho, vejamos o episódio que é relatado por Lisa Wolford (1997b): quando em 1982 decidiu exilar-se da Polónia, Grotowski esperou por uma ocasião em que todos os membros do Teatr-Laboratorium se encontravam fora do país em trabalho. Nessa ocasião informou-os do seu propósito e de que havia um advogado em Paris, onde a maioria se encontrava, pago por ele e preparado para assumir o processo caso alguns deles pretendessem pedir asilo político e eximir-se a represálias.

\footnotetext{
${ }^{18}$ Comunicação pessoal, Novembro de 2018.
}

${ }^{19}$ Poverty was at first a practice of this theatre; only later was it raised to the dignity of aesthetics. (Tradução nossa) 
Também Antonio Attisani entende ${ }^{20}$ que, não tendo Grotowski escrito um código ético, é nas suas acções, nos diferentes momentos da sua vida, que temos que procurar a sua ética. E que a sua vida foi um traçar de novos caminhos da procura do conhecimento, da consciência, com os outros e no meio dos outros. A sua ética é, portanto, a sua história.

Em Grotowski, a ética é o conjunto de princípios que regula a relação com o Outro, no respeito pela sua subjectividade, assente numa relação artísticoprofissional cujo objectivo ontológico é a auto-realização, a Vida. Que não se confunde com a Moral porque "a arte não pode ser limitada pelas leis da moralidade comum, nem pelo catecismo" (Grotowski, 1975 [1968], p. 203). Não se conforma às regras sociais, traduz-se em consciência: "Consciência [...] é completamente diferente do código moral, que pertence à sociedade. Se transgrides o código moral sentes-te culpado, é a sociedade que fala em ti. Mas se agires contra a consciência, sentes remorso". ${ }^{21}$ (Grotowski,1988, p. 54).

\section{A Ética como imperativo profissional}

Mostrei antes como a linearidade e a coerência do percurso de Grotowski nos permitem tomar as suas declarações de qualquer época e aplicá-las à totalidade do seu pensamento. Para entender a sua ética é importante um dos seus mais antigos textos, incluído na edição de Para um Teatro Pobre (1975 [1968]), a Afirmação de Princípios, que é o que mais se aproxima de um código ético. Embora tenha sido escrito no contexto do Teatr-Laboratorium e para uso interno, ele é essencial para a prática e compreensão da totalidade da metodologia de Grotowski. Trata-se de um conjunto de normas requeridas pelo trabalho artístico profissional; são leis do ofício, regras do métier. A sua exigência tem um fundamento técnico-prático e constituem um normativo de decoro profissional,

${ }^{20}$ Comunicação pessoal, Agosto de 2018.

${ }^{21}$ Conscience [...] is different from the moral code which just belongs to society. If you break the moral code you feel guilty, and it is society which speaks in you. But if you do an act against conscience, you feel remorse. (Tradução nossa) 
que, articuladas com o respeito devido a si próprio, se tornam num indispensável imperativo ético.

A Afirmação de Princípios expõe e justifica a exigência de disciplina e a responsabilidade que são requeridas ao actor, estabelece-lhe os objectivos, demarca as exigências da moral das da consciência, estabelece as responsabilidades do encenador, enfim, os códigos de conduta que são habitualmente incutidos nas escolas de teatro, relacionando-os com a prática artística de uma intensidade total. Porque em Grotowski não há meios-termos, tudo é total. Por exemplo:

Um actor tem de estar sempre pronto a entrar no acto de criação no momento exacto determinado pelo grupo. Donde, a sua saúde, as suas condições físicas e todos os seus problemas pessoais deixam de dizer respeito só a ele. Um acto de criação de tal qualidade só resulta se for alimentado pelo organismo vivo. Por isso, temos a obrigação de cuidar diariamente dos nossos corpos, para que estejam sempre prontos para a tarefa. Não devemos privar-nos do sono por motivo dos nossos prazeres pessoais e vir depois trabalhar cansados ou com ressaca (Grotowski, 1975 [1968], p. 207).

O decoro profissional, devido à intensidade requerida pela prática artística, extravasa do ambiente de trabalho e impõe-se também na vida do quotidiano.

O trabalho artístico, a metodologia, é pois composto de técnica e ética. Para Kumiega (1985), a ética enforma o uso da técnica, é o como, o quando, o porquê e o qual da técnica. E, se a metodologia de Grotowski pode ser relevante, a ética, ou a atitude com que é descoberta, procurada e posta em prática, é de primordial significância se tentamos penetrar na essência do trabalho e abordagem de Grotowski.

Só é possível perceber a ética de um Homem conhecendo-o. No caso de Grotowski, só nos restam os seus escritos, poucos, e os testemunhos dos que o conheceram. Do pouco que deixou registado, relevo a entrevista a Schechner, incluída em Para um Teatro Pobre, onde explica: "As pessoas que falam de ética querem, geralmente, impor aos outros um certo tipo de hipocrisia, um sistema de gestos e de conduta que sirva como ética” (Grotowski, 1975 [1968], p. 189). 
Quanto aos testemunhos, o meu, que é pessoal e subjectivo, vai no sentido de que a ética que enforma a metodologia de Grotowski assenta em regras comuns de decoro profissional, que são levadas ao extremo, radicalizadas, mas, porque integram o respeito pela subjectividade do Outro, se mantêm flexíveis, ajustáveis. No que todos os que dedicaram alguma atenção ao assunto parecem concordar é que as técnicas veiculadas por Grotowski só adquirem valor quando orientadas por esse primado ético.

\section{Referências}

ABBAGNANO, Nicola. Dicionário de Filosofia. 5a Edição revista e ampliada. S. Paulo: Martins Fontes, 2007.

BORIE, Monique. Grotowski: D'un théâtre de la régénération à une régénération sans théâtre. Cahiers de l'Est, 12+13, 1978.

BUBER, Martin. I And Thou. Edimburgo: T\&T Clark, 1937 (primeira publicação em alemão em 1923).

BURZYNSKI, Tadeus; OSINSKI, Zbigniew. Grotowski's Laboratory. Varsóvia: Interpress Publishers, 1979.

COELHO, Paula Alves Barbosa. A Experiência da Alteridade em Grotowski. 2009. Tese (Doutoramento em Artes Cénicas) - Universidade de São Paulo, S. Paulo, 2009.

GRIMES, Ronald. The Theatre of Sources. In: SCHECHNER, Richard; WOLFORD, Lisa (eds.), The Grotowski Sourcebook. Londres: Routledge, p. 271 - 280, 1997.

GROTOWSKI, Jerzy. Para Um Teatro Pobre. Lisboa: Forja, 1975 (primeira edição em inglês de 1968 por Odin Teatrets Forlag).

GROTOWSKI, Jerzy. Poszukiwania Teatru Laboratorium. Tribuna Ludu, n. 252, 1976.

GROTOWSKI, Jerzy. Performer. In: GROTOWSKI, Jerzy; BROOK, Peter; BACCI, Roberto. Centro di Lavoro di Jerzi Grotowski. Pontedera: Centro per la Sperimentazione e la Ricerca Teatrale, 1988. 
GROTOWSKI, Jerzy. Discurso de Jerzy Grotowski no Doutoramento honoris causa da Universidade de Wroclaw. Wroclaw: Wydawnictwo Uniwersytetu Wroctawskiego, 1993.

GROTOWSKI, Jerzy. From the Theatre Company to Art as Vehicule. In: RICHARDS, Thomas, At Work With Grotowski on Physical Actions. Londres: Routledge, 1995, p. $115-135$.

GROTOWSKI, Jerzy. Theatre of Sources. In: SCHECHNER, Richard; WOLFORD, Lisa (eds.), The Grotowski Sourcebook. Londres: Routledge, 1997a, p. 252 - 270.

GROTOWSKI, Jerzy. Tu es le Fils de Quelqu'un. In: SCHECHNER, Richard; WOLFORD, Lisa (eds.), The Grotowski Sourcebook. Londres: Routledge, 1997b (primeira publicação em italiano, 1986 por Linea d'ombra no 17), p. 294 - 305.

KOTT, Jan. Why Should I Take Part in the Sacred Dance? In: SCHECHNER, Richard; WOLFORD, Lisa (eds.), The Grotowski Sourcebook. Londres: Routledge, 1997, p. 134 -140 .

KUMIEGA, Jennifer. The Theatre of Grotowski. Londres: Mathuen, 1985.

LAVY, Jennifer. Theoretical Foundations of Grotowski's Total Act, Via Negativa, and Conjunctio Oppositorum. The Journal of Religion and Theatre, Vol. 4, No. 2, p. 175 - 188, 2005.

MOTA LIMA, Tatiana. Palavras Praticadas: O Percurso Artístico de Jerzy Grotowski, 1959-1974. S. Paulo: Perspectiva, 2012.

OSINSKI, Zbigniew. Returning to the Subject: The Heritage of Reduta in Grotowski's Laboratory Theatre. TDR Vol. 52, No. 2, p. 52 - 74, 2008.

RICHARDS, Thomas. At Work With Grotowski on Physical Actions. Londres: Routledge, 1995.

SCHECHNER, Richard. Introduction to part II. In: SCHECHNER, Richard; WOLFORD, Lisa (eds.), The Grotowski Sourcebook. Londres: Routledge, 1997, p. 207 - 214.

SLOWIAK, James; CUESTA, Jairo. Jerzy Grotowski. Londres e Nova Iorque: Routledge, 2007.

THIBAUDAT, Jean-Pierre. Grotowski, un véhicule du théâtre. Liberation. Paris, p. 28 - 30, 26 Julho, 1995.

WOLFORD, Lisa. Grotowski's Objective Drama Research. Jackson: University Press of Mississippi, 1996.

WOLFORD, Lisa. Introduction to part IV. In: SCHECHNER, Richard; WOLFORD, Lisa (eds.), The Grotowski Sourcebook. Londres: Routledge, 1997a, p. 367 - 375. 
WOLFORD, Lisa. Introduction to part III. In: SCHECHNER, Richard; WOLFORD, Lisa (eds.), The Grotowski Sourcebook. Londres: Routledge, 1997b, p. 283 - 293.

Recebido em: 01/10/2020

Aprovado em: 21/11/2020 